\title{
Implicaciones de la reglamentación del sistema prostitucional en la igualdad sexual: el caso alemán Implications of the regulation of the prostitutional system in sexual equality: the german case
}

\author{
Laura Nuño Gómez \\ Universidad Rey Juan Carlos \\ laura.nuno@urjc.es
}

Recibido / received: 30/01/2018

Aceptado / accepted: 09/07/2018

DOI: https://doi.org/10.20318/eunomia.2018.4345

\begin{abstract}
Resumen
La abolición de la prostitución ha sido un objetivo y una pretensión histórica del movimiento y la teoría política feminista. Sin embargo, la propuesta de considerarla como una actividad más en el marco de las relaciones laborales se presenta ahora como una urgente innovación normativa encaminada, supuestamente, a garantizar los derechos de las mujeres prostituidas. Pero esta demanda no es ajena a la transformación que ha sufrido la prostitución como actividad, que representa en la actualidad un lucrativo mercado global con dimensiones sistémicas. El presente artículo analiza los componentes estructurales del sistema prostitucional y las implicaciones de su reglamentación en la igualdad sexual para evaluar los efectos concretos de su reglamentación en el caso alemán.
\end{abstract}

\section{Palabras clave}

Prostitución, Trata de seres humanos (TSH), Políticas Públicas, Explotación Sexual, Igualdad de género, Derecho Internacional Público.

\begin{abstract}
The abolition of prostitution has been an objective and a historical demand of both the feminist movement and feminist political theory. However, the proposal of consideration as any other activity in the framework of labor relations, is now portrayed as an urgent regulatory innovation aimed, supposedly, at guaranteeing the rights of prostituted women. But this claim must be interpreted in relation with the transformation of prostitution as an activity, which currently represents a lucrative global market with systemic dimensions. This article analyzes the structural components of the prostitution system and the implications of its regulation on gender equality in order to evaluate the particular effects of its regulation in the German case.
\end{abstract}




\title{
Keywords
}

Prostitution, Trafficking in Human Beings (THB), Public Policies, Sexual Exploitation, Gender Equality, Public International Law.

\begin{abstract}
SUMARIO. 1. Cuerpos sexuales, cuerpos reproductivos. 2. La nueva racionalidad neoliberal y los negocios de la vulnerabilidad. 3 . Tres falsas premisas del discurso reglamentarista. 4. Estudio de caso: el modelo reglamentarista alemán. 5. Conclusiones.
\end{abstract}

\section{Cuerpos sexuales, cuerpos reproductivos}

Si hay un objetivo común que caracterice históricamente a los patriarcados, es la pretensión de uso sexual y reproductivo de las mujeres (Mackinnon, 1989: 299). Con tal finalidad, no se ahorran esfuerzos en normativizar los mandatos de género necesarios para promover el beneplácito o la aquiescencia de las mismas. Tradicionalmente, con la finalidad de garantizar una función reproductiva que ofreciera certezas sobre el origen de la descendencia de los varones, se privatizó su sexualidad en el marco de la institución matrimonial. Pero su privatización no resolvía el derecho sexual patriarcal de acceder al cuerpo de varias mujeres, de un abanico de féminas en general. Para ello, era preciso disponer de mujeres que, lejos de privatizarse, se colectivizaran a través de una segunda institución: la prostitución. Una doble moral sexual, enmarcada en el orden normal y natural de la sociedad, cuya deslegitimación ha sido un objetivo histórico del sufragismo y del feminismo posterior ${ }^{1}$, muy críticos ambos con las implicaciones y consecuencias del contrato sexual, tematizado por Pateman, ya fuera tanto en su versión matrimonial como prostitucional (De Miguel y Palomo, 2011).

En la cultura cristiana, la mujer promiscua que desafía el mandato de una sexualidad encaminada a la procreación en el ámbito del matrimonio canónico se consideró, y aún se considera, "contraria a la buena sexualidad, a la sexualidad cristiana: es la mala, la no dicha" (Lagarde, 2001: 575). Sin embargo, destacados moralistas defendieron -en no pocas ocasiones- la existencia de mancebías como un "mal menor". El propio San Agustín, en el capítulo cuarto del Libro segundo de "De Ordine"2, mantuvo que, si bien la prostitución era un oficio degradante, contribuía al orden ajeno. Según sus tesis, al igual que las ciudades precisan de la existencia de sumideros y cloacas para canalizar o evacuar los deshechos, los burdeles cumplen el mismo fin: ordenan la sexualidad (buena y mala), concentrando los actos de lujuria en un reducto concreto y con mujeres determinadas.

El argumento de fondo parece sustentarse en que, habida cuenta que los instintos sexuales del supuesto sexo de la razón son irrefrenables, pero su expectativa es la de gozar del monopolio sexual de mujeres privadas, han de destinarse unas mujeres para estricto uso privado y otras para acceso público. Una distribución que permite, por una parte, garantizar la monogamia de aquellas destinadas a la reproducción y la preservación de la estirpe masculina $\mathrm{y}$, por otra, ofrecer la disponibilidad sexual de mujeres variadas para los varones que así lo deseen en cualquier momento o circunstancia. De forma tal que, todas las comunidades

\footnotetext{
1 Unanimidad existente casi hasta la década de los años ochenta y noventa del siglo XX, etapa en la que se rompe en consenso existente hasta la fecha en la consideración de la prostitución como una forma específica de opresión de las mujeres.

2 Publicado bajo el título "Si el hombre, haciendo mal, obra con orden. Los males ordenados contribuyen al decoro del universo".
} 
humanas han tenido a lo largo de la historia mujeres destinadas a ambos usos, diferenciando convenientemente a unas y otras.

Porque el orden social patriarcal no sólo garantiza la disponibilidad de mujeres para uso privado y público, sino que establece una férrea frontera entre las mujeres destinadas a estos fines. En el caso de las mujeres privadas y, en la medida que el control de la actividad sexual de las mujeres permite controlar la reproductiva, su sexualidad y la propia exposición de su cuerpo frente a terceros, ha estado rodeada de un sinfín de mandatos punitivo-moralizadores. De forma tal que, los patriarcados de coerción ${ }^{3}$, administran la privatización de su sexualidad a través de severos códigos familiares y culturales que garantizan la virginidad antes del matrimonio y la fidelidad conyugal.

En los patriarcados por consentimiento, por el contrario, los cambios sociales y legislativos fueron restando fuerza a dichos mandatos. A raíz de la década de los sesenta, en las sociedades que vivieron la denominada revolución sexual, se rebajó la sanción social sobre la libertad sexual de las mujeres. El erotismo, el deseo y el placer sexual femenino perdieron su condición de tabú, su presencia en el espacio público se fue normalizando y las relaciones fuera del ámbito matrimonial se desestigmatizaron. Pero los avances en libertad sexual, así como la pretensión de las mujeres de adquirir el ansiado estatuto de sujeto (dejando atrás su consideración de objeto) se vieron acompañados de una "reacción" " que reforzó y exaltó el mandato de ser un cuerpo atractivo (entendido como esbelto, joven y disponible).

En pleno siglo $X X I$, en mayor o menor medida, la socialización sigue promoviendo la consideración de las mujeres como objetos sexuales que se valoran en función del atractivo o reclamo que suscita en terceros (Wolf, 1992; Greer, 2004). Una reificación de la identidad femenina que alimenta algunas formas de violencia de género como es el caso de la prostitución, la pornografía o cualquier forma de violencia sexual. Por ello, aunque la revolución sexual acabó con algunas restricciones impuestas específicamente a las mujeres, no significó el abandono de un particular esencialismo que las convierte en cuerpos sexualizados.

A su vez, la rígida sanción previa de las relaciones fuera del ámbito conyugal se tornó en irrelevancia de las relaciones sexuales o incluso en un mandato de accesibilidad y de prácticas sexuales lesivas ${ }^{5}$, emuladas de la pornografía, cada vez más frecuentes entre la población más joven. En cualquier caso, y en la medida que la disponibilidad sexual ya no determina la esencia de las mujeres o la histórica distinción entre malas y buenas, se ha banalizado su mercantilización.

Por ello, aunque es cierto que las mujeres se han vendido y comprado a lo largo de la historia para su uso sexual, nunca ha sido con las dimensiones actuales ${ }^{6}$. En la actualidad, la prostitución representa un lucrativo mercado global en expansión

\footnotetext{
${ }^{3}$ Según la clasificación de Puleo (1995: 29), conviene advertir que la misma "es un esquema orientativo y no puede ser considerada como absoluta. Todo sistema patriarcal se basa en la coerción y en el consentimiento".

${ }^{4}$ Según terminología de Faludi (1993).

${ }^{5}$ Como representa el caso de la práctica sexual denominada "el muelle". Para más información: A. V. C. (2017). "Qué es el 'juego del muelle' y por qué es tan peligroso para la salud", 9 de enero de 2017. Disponible en: https://www.elconfidencial.com/alma-corazon-vida/2017-01-09/juego-muelle-que-esruleta-sexual-adolescentes 1313845/ (fecha de consulta: 3 de julio de 2018).

${ }^{6}$ Como afirma Amelia Valcárcel "toda sociedad patriarcal que quiere comprar mujeres logra hacerlo. $Y$ las sociedades también patriarcales pobres las venden. No es que ellos no las compraran si estuvieran en la situación de hacerlo, es que digamos se ven en la de venderlas. Y las venden. De tal manera que ocurre un enorme e intenso tráfico de mujeres a lo largo de todo el planeta, desde hace bastante tiempo. No es de hoy, aunque es más grave hoy" (De Miguel, 2014: 203).
} 
con una estructura sistémica. Un crecimiento no ajeno a la trivialización de su mercantilización y consumo, pero tampoco a la creciente feminización de la pobreza, con el consecuente incremento de las situaciones de vulnerabilidad de las mujeres, y al lucro que genera el mercado prostitucional (Cobo, 2017). Sin ir más lejos, en España y según los datos ofrecidos por la Asociación Nacional de Empresarios de Locales de Alterne (ANELA), los beneficios anuales por cada mujer prostituida ascendían, hace diez años, a 45.000 euros anuales ${ }^{7}$.

Esta realidad contrasta con la demanda de reglamentar la prostitución como una forma de transgredir un supuesto orden; uno no muy distinto al que San Agustín pretendía preservar con su reconocimiento. Según parece, la legalización de una institución que se construye en el imaginario colectivo como "el oficio más antiguo" e interpretada como un "mal menor" por destacados teólogos y moralistas, se presenta como una suerte de innovación normativa vinculada a la libertad y a la revolución sexual de las mujeres. Una institución histórica patriarcal, en expansión gracias a la creciente racionalidad neoliberal que explota las desigualdades Norte-Sur, integrada en el ámbito de la Unión Europea mayoritariamente por mujeres migrantes ${ }^{8}$, se presenta como una sugerente invitación a la transgresión. Las razones del lobby del mercado prostitucional, se pueden entender, aunque no compartir. Lo paradójico es que como tal sean aceptadas por aquellos discursos o posicionamientos políticos pretendidamente anticoloniales, anticapitalistas, defensores de los derechos humanos o feministas y contrarios al orden patriarcal y neoliberal que las sustenta.

\section{Cuerpos sexuales, cuerpos reproductivos}

La explotación sexual de mujeres y niñas es un fenómeno transversal al patriarcado. Como se apuntaba con anterioridad, a efectos de garantizar un completo usufructo, a lo largo de la historia, han variado usos, formas y maneras de ejercer la misma. En la actualidad, la prostitución representa un negocio en expansión que permite colectivizar la explotación sexual de las mujeres en el que confluyen la racionalidad y los intereses del patriarcado y el neoliberalismo. Ambos conforman un sistema orientado a generar las condiciones necesarias para garantizar tanto el derecho patriarcal de uso sexual de las mujeres como el lucro que supone su mercantilización.

La alienación o expropiación de la sexualidad femenina característica del patriarcado ha encontrado un estratégico aliado: un sistema neoliberal según el cual todo puede ser considerado una mercancía más. Se puede comprar el cuerpo de las mujeres con fines sexuales o reproductivos ${ }^{9}$, convertir en activos financieros las especies en extinción o hacer un buen negocio de las situaciones de indigencia o vulnerabilidad. Las economías de mercado se han transformado en sociedades de mercado que propugnan un proyecto de vida basado en tener deseos y satisfacerlos (Sandel, 2013). El modelo de consumo impuesto fomenta el "usar y tirar" y la sacralización de la novedad en un mercado donde el precio o el dinero libera al consumidor/a de cualquier responsabilidad ética o moral (Simmel, 1990). De forma tal que es legítimo comprar todo lo que se encuentre en venta, siempre que se tenga capacidad económica para ello.

A diferencia del capitalismo, el neoliberalismo no remite solo a un modelo económico, sino también a una nueva forma de racionalidad que sublima el

\footnotetext{
${ }^{7}$ Datos aportados por ANELA (Congreso de los Diputados, 2007: 48).

8 Según la Red TAMPEP (2017), creada por la Fundación holandesa Graaf y una conocida plataforma defensora de la reglamentación, entre $70-80 \%$ de las mujeres prostituidas en Europa son migrantes. Informe disponible en la siguiente dirección: https://tampep.eu/wp-content/uploads/2017/11/TAMPEPpaper-ESP.pdf (fecha de consulta: 3 de julio de 2018).

${ }^{9}$ Como en el caso de la gestación subrogada o los vientres de alquiler y la venta de óvulos.
} 
individualismo del libre acuerdo y considera los cuerpos elementos subalternos a la economía de mercado; ya sea como medios de producción o como bienes de consumo (Moscoso, 2017). Y, desde esta nueva racionalidad, el lobby de la industria del sexo ha lanzado una poderosa campaña que -bajo el discurso de la protección de lo que denominan trabajadoras sexuales- reclama la legalización de la lucrativa industria del sexo y, con ello, de la explotación sexual ajena.

Si bien es cierto que el sistema prostitucional es un mercado cada vez más globalizado, hay territorios donde su fortaleza es mayor. En concreto, en nuestro país, una tercera parte de los españoles $(32,1 \%)$ declara haber pagado por mantener relaciones sexuales ${ }^{10}$; proporción diez puntos superior a la observada en la media europea. A su vez, la oferta de las tres "s" (sol, sangría y sexo) es un reclamo implícito en muchas agencias internacionales de viajes cuyo destino es nuestro país (Guilló y Santiago, 2017). Por lo que, al elevado consumo local, se suma un turismo que considera la prostitución como una oferta de ocio más.

La rápida expansión de la industria del sexo ha incrementado la demanda de mujeres disponibles para atenderla. Pero, como no es suficiente el número de las que están dispuestas a dedicarse a tal menester de forma voluntaria, es una práctica frecuente proveer los burdeles con mujeres -menores o muy jóvenes- forzadas a ello. El neoliberalismo sexual ${ }^{11}$ y la industria del sexo están rentabilizando las contrageografías de la globalización ${ }^{12}$, la creciente feminización de la pobreza y la existencia de fronteras cada vez más infranqueables en los países más favorecidos. Mafias supuestamente vinculadas al tráfico de personas que utilizan el señuelo de las oportunidades en destino y la clandestinidad o vulnerabilidad que acompaña al tráfico, para practicar la trata con fines de explotación sexual (Thill, 2017). De forma tal que, en la actualidad, el tráfico y la trata con fines de explotación sexual se han convertido en el principal suministrador de un mercado prostitucional ${ }^{13}$ que reclama variedad, sumisión y juventud a precios competitivos ${ }^{14}$.

En concreto, en el caso español, se estima que entre el $90 \%$ y el $95 \%$ de las mujeres prostituidas son víctimas de trata ${ }^{15}$. La estratégica situación territorial, convierte el territorio en una puerta de entrada por el sur de Europa, siendo ruta preferente para la trata de mujeres con fines de explotación sexual y uno de los cinco países europeos con mayor número de traficantes ${ }^{16}$. Un dato que, paradójicamente, convive con la percepción de que los casos de trata en el mercado prostitucional son

\footnotetext{
10 De los cuales dos de cada tres (68,2\%) afirma haberlo hecho en más de una ocasión. Encuesta Nacional sobre Salud sexual. Centro de Investigaciones Sociológicas (ES2780: 22), 2009. Ámbito estatal, tamaño muestral 9850 entrevistas. Por su parte, la UNODC elevaba dicha proporción al 39\% de los hombres, veinte puntos porcentuales por encima de la media europea (UNODC, 2010).

11 Según acepción de Miguel (2016).

12 En el sentido apuntado por Sassen (2000).

${ }^{13}$ Es decir, de un abuso de poder o situación de vulnerabilidad que reúne los requisitos exigibles para la consideración de trata seres humanos con fines de explotación sexual. En el caso español, se estima que entre el $90 \%$ y el $95 \%$ de las mujeres prostituidas son víctimas de trata.

${ }^{14}$ En la actualidad se estima que entre 1,3 y 4,4 millones de mujeres y niñas en el mundo se encuentran explotadas por las redes de trata sexual. La UNODC (2012) cifra en dos millones y medio el número de personas objeto de trata de seres humanos. Entre las cuales, dos terceras partes son mujeres o niñas que el $79 \%$ de las ocasiones tienen fines de explotación sexual, proporción que en su traducción numérica representa un millón trescientas mil mujeres y niñas. ONU Mujeres eleva la estimación sobre trata con fines de explotación sexual a cuatro millones cuatrocientas mil personas, entre las mimas el $98 \%$ son mujeres.

15 Proporción que se corrobora a escala mundial. Ver, entre otros, Congreso de los Diputados (2015).

16 "España, quinto país de la eurozona donde más aumenta el PIB por la contabilización de prostitución y drogas", Europa Press, 17 de octubre de 2014 (fecha de consulta: el 5 de septiembre de 2015).
} 
hechos aislados, cuando es la prostitución voluntaria, no la trata, lo que constituye un fenómeno marginal (Nuño, 2017).

Paradójicamente, el aparente rechazo que suscita la trata se ignora en la consideración de la prostitución. En Europa, donde las prácticas sexuales con menores cuentan con un severo repudio penal y social, la mitad de los compradores siguen pagando por servicios sexuales incluso cuando tienen signos claros que acreditan que son menores de 18 años y, por tanto, víctimas de trata (Honeyball, 2014: 7$)^{17}$. Sin ir más lejos, en España el $44 \%$ de los puteros ${ }^{18}$ manifiesta, abiertamente, que no informaría a la policía si constatara una situación de trata (Meneses et al., 2015).

Un negocio que se alimenta y reproduce la jerarquía sexual, posible gracias a la situación de vulnerabilidad de muchas mujeres, pero que cuenta con el beneplácito de instituciones como el Banco Mundial o el Fondo Monetario Internacional, que aprueban tácitamente una práctica que cumple con el deber de las naciones deudoras de explotar y exportar "todos sus recursos naturales", mujeres incluidas (Federici, 2013: 120). En el caso de la Eurozona, los beneficios generados pueden incluso computarse como Producto Interior Bruto (PIB) ${ }^{19}$.

En la práctica, convive cierta tolerancia social e institucional con un sistema prostitucional muy lucrativo ${ }^{20}$ mientras que las mujeres prostituidas son esencializadas y estigmatizadas por su actividad; máxime si carecen de recursos y ejercen en lugares públicos. De forma tal que, el repudio social se proyecta sobre la víctima y no sobre el victimario. Una percepción que no es ajena a la consideración de las mujeres como cuerpos sexualizados, a la normalización de su uso sexual y a que el lucrativo negocio del mercado del sexo permite financiar grupos de presión, ONG ${ }^{21}$, campañas y costosos bufetes profesionales que normalizan o glamourizan la prostitución.

\section{Tres falsas premisas del discurso reglamentarista}

El panorama descrito, lógicamente, obliga a buscar posibles soluciones. Sin embargo, las propuestas reglamentaristas que proponen considerar la prostitución como una profesión o un oficio cualquiera en el ámbito de las relaciones laborales tienen implicaciones nocivas tanto para las mujeres en prostitución como para la igualdad de género ${ }^{22}$.

\footnotetext{
17 Informe sobre la explotación sexual y la prostitución y su impacto en la igualdad de género. Parlamento Europeo (2013/2103(INI)), conocido como Informe Honeyball en honor a la eurodiputada británica Mary Honeyball, que fue relatora del mismo.

${ }^{18}$ Siguiendo las recomendaciones de Gómez, Á., Pérez, S. y Verdugo, R. M. (2015), se opta por utilizar el término "putero" para evidenciar la actividad y evitar la legitimación o normalización con conlleva el término cliente.

${ }^{19}$ Como en los países de la Eurozona.

${ }^{20}$ Posible gracias a las ventajas de evitar el debate sobre el origen o las causas por las que una mujer es prostituida y convertir la misma en autonomía de las mismas o libre elección.

${ }^{21}$ Como se desprende de las declaraciones uno de los proxenetas entrevistados por Mabel Lozano en El proxeneta, es práctica habitual que el dinero negro de los prostíbulos se blanquee en compras de obras de arte o inmuebles y que se hagan donaciones a algunas ONG a efectos de aplicar las oportunas desgravaciones fiscales (Lozano, 2017).

22 En la medida que, como señala De Miguel (2012), la prostitución representa una escuela de desigualdad humana
} 
En primer lugar, hace más de seis décadas, el Derecho internacional ya calificó la prostitución como una violación de los Derechos Humanos ${ }^{23}$ y, por tanto, legalizarla supondría avalar algunas formas y modos en que es lícita tal violación. Olvidando este aspecto, nada irrelevante, el discurso reglamentarista asume como ciertas, al menos, tres premisas falsas: 1) la sexualización de las mujeres y lo sexual como algo innato o natural y, por tanto, la posición abolicionista como represiva, puritana o antisexo; 2) la validez del consentimiento o la libre elección individual en contextos de opresión o vulnerabilidad y el paternalismo desempoderante de un abolicionismo que las considera víctimas; y 3 ) la reglamentación como un sistema que pone límites a la opresión, que empodera y garantiza los derechos de las mujeres prostituidas.

Respecto a la primera cuestión y, en la medida que la actividad sexual conlleva un componente relacional, procede analizar si es ciertamente algo innato o si -por el contrario- está mediada por relaciones de poder (Barry, 1994; Greer, 2004; entre otras). Como señalara hacer cuatro décadas Kate Millett (1977), el coito no ocurre en el vacío, es una relación de poder. Un placer que en la prostitución sólo existe para una parte, los sujetos sexuales, y no para el objeto sexual. El placer de las mujeres prostituidas es irrelevante, aunque se exige una performatividad que aparente reciprocidad en la satisfacción sexual. Y en dicha puesta en escena, es frecuente que el putero espere de la "puta" un ejercicio de representación que exprese entrega, deseabilidad o incluso un "final feliz" compartido. Un proceso que obliga a una desconexión entre el cuerpo y el ser de la mujer en prostitución, con graves implicaciones identitarias que ello conlleva ${ }^{24}$.

$\mathrm{Si}$, efectivamente, median relaciones de poder, no cabría hablar de algo innato, natural o personal sino de un contexto en el que puede operar una opresión o explotación con evidentes consecuencias personales, colectivas y políticas. Problematizar o politizar la sexualidad -como ya lo hiciera el feminismo radical de los años sesenta y setenta- no representa una posición puritana o contraria a la libertad sexual, sino que, por el contrario, supone evaluar críticamente cuan autónoma es esa proclamada libertad. Se trata de analizar si hay prejuicios asumidos de forma acrítica, si de ello se derivan contextos de subordinación o subalternidad y, en última instancia, politizar los modelos de masculinidad y feminidad que reproduce la prostitución y evidenciar si conducen a relaciones más justas e igualitarias o no.

Y de ello se deriva la segunda falsa premisa: la supuesta libre elección. Conviene advertir que la Teoría del consentimiento impide cualquier posible lectura de la opresión y oculta los condicionantes sistémicos que determinan esa supuesta libertad (De Miguel, 2016). Deliberadamente, ignora el perfil de dichas mujeres y su contexto biográfico, sus alternativas reales o cuál sería el "plan B" en caso de no consentir. En última instancia, el argumento de la libre elección ignora si la libertad es tal y si se dan los requisitos éticos que permiten hablar de consentimiento informado. Pero no solo falsea tal consentimiento, sino que en la medida que individualiza la decisión, la despolitiza. Para el caso que nos ocupa, se niega el componente estructural o sistémico de la prostitución. Entre otros, la sexualidad patriarcal, la jerarquía sexual y el hecho irrefutable de que esta se alimenta, fundamentalmente, de mujeres y niñas en situación de vulnerabilidad.

En la medida que el consentimiento responsabiliza a la víctima de su opresión, la desvictimiza. Como señala Ekis Ekman (2017: 66), "al igual que todos los sistemas que aceptan las desigualdades, el orden neoliberal odia a las víctimas" y la propia

\footnotetext{
${ }^{23}$ En concreto, en la Convención para la erradicación de todas las formas de discriminación contra la mujer (CEDAW, 1979) y en el Convenio para la Represión de la trata de personas y la explotación de la prostitución ajena (1949).

${ }^{24}$ Que frecuentemente expresan las mujeres en prostitución (Ekis Ekman, 2017: 153-154).
} 
consideración de víctimas es interpelada por el discurso reglamentarista como práctica desempoderante. Mantienen que tal calificación resta agencia y atribuye un papel pasivo a las mujeres. Se parte, así, de una maniquea esencialización de los seres humanos entendidos como víctimas débiles y pasivas o como sujetos fuertes y activos. De forma tal, que el contexto de opresión define la ontología y el carácter de una víctima, devaluando su consideración individual y percepción social, pero no así la de su victimario.

Una lectura que contrasta, a su vez, con la reclamación y el reconocimiento internacional del Estatuto de víctimas como consecuencia de represiones políticas, guerras o genocidios, por ejemplo. Deliberadamente parece olvidarse también que, a lo largo de la vida, todas las personas pueden ser víctimas de una opresión o una violencia concreta, sin que ello determine invariablemente su identidad. Muy al contrario, la pretensión de evitar su consideración como víctimas, lejos de empoderarlas, soslaya -cuando no impide- el deber de verdad, justicia y reparación que debiera asistirlas.

A su vez, para que el consentimiento sea válido ha de ser un acto libre, no mediado por situaciones de supervivencia, subordinación o inevitabilidad. En un contexto globalizado de feminización de la pobreza y en el que los cuerpos de las mujeres siguen considerándose -en mayor o menor medida- elementos subalternos destinados a cumplir expectativas ajenas, es preciso desmitificar un supuesto consentimiento en el que no se garantiza la autonomía exigible a un contrato libre entre iguales ${ }^{25}$.

Un acuerdo individual entre partes, si una de ellas se encuentra en un contexto de necesidad o desigualdad, sin opciones alternativas, es una ficción que permite legitimar servidumbres bajo el paraguas de una libertad que no es tal. Recurrir al mantra del consentimiento no solo elude el contexto de dominación, sino que proyecta un imaginario que responsabiliza a las víctimas de su propia explotación y libera de cualquier responsabilidad a los victimarios. Por ello, en un mundo atravesado por fuertes desigualdades de género y clase, es preciso desmitificar y politizar un consentimiento que no hace sino ocultar y legitimar la explotación sexual de las mujeres (Fraisse, 2011).

La tercera y última línea argumental en la defensa del modelo reglamentarista es que, frente al "mal mayor" que supone su no regulación, se debe adoptar un marco legal permitiría garantizar los derechos de las mujeres en prostitución. Un posicionamiento instalado en la conocida como "política de hechos consumados" que no se aplica, por ejemplo, al ámbito de las relaciones laborales, al tráfico de órganos, a la corrupción o al cambio climático, por poner sólo algunos ejemplos.

Para avalar sus pretensiones, el discurso reglamentarista defiende hablar en nombre y representación de los intereses de "I@s trabajador@s del sexo". Sin entrar a debatir la farsa que supone el uso de un lenguaje no sexista en una actividad claramente generizada ${ }^{26} \mathrm{y}$, como puede desprenderse del caso alemán, su regulación no garantiza protección alguna para las mujeres en prostitución ni es una demanda de la gran mayoría de ellas.

A su vez, entre las posiciones teóricas o los colectivos que defienden las bondades de la reglamentación, no hay representación del colectivo mayoritario de

\footnotetext{
${ }^{25}$ Para un análisis previo referido específicamente al debate sobre la maternidad subrogada o comercial, consultar Nuño $(2016,683-700)$.

${ }^{26}$ Donde la inmensa mayoría de las personas que prestan "servicios sexuales" son mujeres.
} 
mujeres prostituidas: las victimas de trata ${ }^{27}$. La portavocía de sus intereses recae, fundamentalmente, en supuestos sindicatos que tienen una composición y funcionamiento bastante peculiar. Como revela la investigación realizada recientemente por la periodista Ekis Ekman, el Sindicato Internacional de Trabajadores sexuales (IUSW), afincado en Gran Bretaña, está dirigido por Douglas Fox, un destacado miembro de la patronal de los negocios de alterne. A diferencia de otros sindicatos, para ser miembro del IUSW no es preciso "trabajar" en el sector, cualquiera puede miembro de estos peculiares sindicatos: dueños de burdeles, puteros o público en general. Una dinámica que se replica en sindicatos homólogos del entorno europeo como es el caso del sindicato francés Le Syndicat de Travail Sexual (STRASS), el holandés Rode Draad o el alemán ver.di.

Aunque la tasa de mortalidad entre las mujeres y niñas que ejercen la prostitución es cuarenta veces superior a la media, no se conoce conflicto laboral ni denuncia alguna promovida por dichos sindicatos contra la patronal del sexo. Los burdeles parecen ser centros de trabajo donde reina la concordia laboral y la seguridad e higiene en el trabajo. Una idiosincrasia que, como señala Ekis Ekman (2017: 113), quizás se deba a que "hay muchas cosas que no son lo que parecen. Los sindicatos no son sindicatos. Los grupos de prostitutas son, al mismo tiempo, grupos de propietarios de burdeles. El principal engaño es que la propaganda a favor de los derechos de los trabajadores sexuales no tiene por objeto transformar la institución de la prostitución en sí misma, se trata, estrictamente, de cambiar la imagen de la prostitución".

Por ello, la reglamentación, como se muestra a continuación, ni dignifica ni empodera a las mujeres prostituidas. Dignifica y empodera a proxenetas y tratantes. Transforma una violación de los derechos humanos en una forma de ocio y un símbolo de la libertad sexual. Una ecuación perfecta que permite que uso y negocio sigan su curso, sin que nada empañe la diversión.

\section{Estudio de caso: el modelo reglamentarista alemán}

La regulación alemana, que cuando menos cabe calificar de ingenua, partía de una legislación previa que consideraba la prostitución como una práctica inmoral (art. 138 del Código Civil). La reforma emprendida se sustentó en la premisa de que el trauma de las mujeres en prostitución se debía a la falta de regulación de la actividad y de las implicaciones sociales, laborales y personales que de ello se derivaban. Convirtiéndolas en trabajadoras sexuales, trauma y estigma desaparecerían, podrían afiliarse a la seguridad social y garantizar, con ello, el ejercicio de sus derechos civiles y laborales o incluso denunciar a un cliente en caso de impago.

Sin embargo, se ignoró que gran parte del estigma viene asociado a su situación de pobreza y vulnerabilidad, no a la actividad (Gimeno, 2012: 191). Tampoco pareció tenerse en cuenta que la dinámica habitual en el sector es cobrar el "servicio" de antemano y que, de no ser así, en caso de desacuerdo, el anonimato de los puteros impide una posible reclamación económica posterior. A su vez, las prestaciones sanitarias son independientes de la actividad en concreto que se desarrolle, por lo que su cobertura asistencial no quedaba ligada al reconocimiento de la prostitución como un trabajo en el marco de las relaciones laborales. Por el contrario, como externalidad negativa a su reglamentación, la prostitución dejó de considerarse una pretensión abusiva o ilegal en el ámbito de la sociedad en general y de las relaciones

\footnotetext{
27 Sin embargo, sí existen activistas víctimas de trata en el movimiento abolicionista. En el contexto español, por ejemplo, la feminista Amelia Tiganus
} 
laborales o de la formación profesional en concreto, para pasar a ser una especialización profesional como otra cualquiera.

El resultado, quince años después de la aprobación de la ley, es demoledor. De las 400.000 mujeres que se estimaba ejercían la prostitución en el país en 2002, solo 44 (el $0,01 \%$ del total) ${ }^{28}$ se han registrado oficialmente en dicha categoría laboral y la mayoría carece todavía de servicios mínimos de atención sanitaria. Los macroburdeles ubicados en las proximidades de los aeropuertos internacionales han proliferado, muchos de los cuales pueden acoger hasta un millar de puteros a la vez. También ha promovido el proxenetismo a pequeña escala en calles, garajes o incluso cabañas. Porque si la actividad es legal, cualquier espacio o lugar representa una oportunidad de negocio.

La comercialización normalizada de los servicios sexuales ha producido un abaratamiento de las tarifas, por lo que la remuneración que perciben las mujeres es ahora bastante menor. Un único "servicio sexual" puede tener un coste que oscila entre los 30 euros en los lugares más lujosos a los 5 euros, si se ofrece en la vía pública. La conocida tarifa plana (más conocida como "all you can fuck"), que ofertan los principales macroburdeles, permite que por 60 o 70 euros diarios se acceda a sexo ilimitado con todas las mujeres disponibles en un determinado local ${ }^{29}$. La frecuente hospitalización de aquellas que han de atender la llegada de vuelos chárter de turistas sexuales que acuden al reclamo de la tarifa plana, provocó que en julio de 2017 se acometiera una reforma legislativa para prohibir dichas promociones o paquetes comerciales. Sin embargo, bajo otras denominaciones, sigue ofreciéndose tanto por agencias internacionales de viajes como por burdeles locales.

La actividad no sólo está peor remunerada, sino que es cada vez más intensa, peligrosa y lesiva. Se ha incrementado la violencia física o psicológica y las mujeres en prostitución tienen, como promedio, tan sólo cinco horas diarias para el descanso ${ }^{30}$. Los clientes, legitimados por la legalidad de un mercado que se percibe como una forma de ocio más y dónde todo es cuestión del precio que se esté dispuesto a pagar, exigen nuevos servicios como prácticas sexuales con mujeres en avanzado estado de gestación que atienden un número de hombres diarios que oscila entre los 15 y los 40 .

Como señala la dominatrix Ellen Templin en una entrevista radiofónica concedida ocho años después de la aprobación de la ley alemana, "a partir de la reforma, podemos constatar que no solamente los anuncios son cada vez más desinhibidos, sino que los compradores de sexo son cada vez más brutales". Cuando nos negamos a realizar algo, a menudo nos responden: "es tu trabajo" ${ }^{31}$. Existen

\footnotetext{
${ }^{28}$ Proporción que cabría calificar de inferior habida cuenta que se estima que su número se ha incrementado desde el año 2002, al menos, un $30 \%$.

${ }^{29}$ Es habitual que la tarifa incluya la invitación a una cerveza y una típica salchicha alemana.

30 Datos corroborados en numerosas investigaciones periodísticas. Entre otras, SCHÄFER, T. (2017), "La nueva ley de prostitución alemana prohíbe la tarifa plana de sexo", 26 de junio. Disponible en: https://www.lamarea.com/2017/06/26/fin-de-la-tarifa-plana-de-sexo-en-alemania/ (fecha de consulta: 3 de julio de 2018) y KRAUS, I. y MAIER, U. (2016), Medien und Prostitution. Disponible en: https://somoslamitad.wordpress.com/2016/11/14/el-modelo-aleman-esta-creando-el-infierno-en-latierra/ (fecha de consulta: 3 de julio de 2018).

31 Entrevista disponible en la siguiente dirección electrónica: http://www.wuestewelle.de/redaktion/view/id/114/tab/weblog/article/34860/Interview_mit_einer_Domina.html, citado Ingeborg Kraus en la Conferencia de Madrid: "La prostitución es incompatible con la igualdad entre hombres y mujeres", organizada por la "Comisión para la investigación de malos tratos a mujeres". Disponible en la siguiente dirección electrónica: http://www.tribunafeminista.org/2017/03/puteros-contarifa-plana-en-alemania-60e-por-una-cerveza-una-salchicha-y-acceso-ilimitado-a-mujeres/. (fecha de consulta: 3 de julio de 2018).
} 
cartas o menús de servicios accesibles para cualquiera en internet ${ }^{32}$, es frecuente que se intenten reclutar mujeres jóvenes en las calles de las ciudades alemanas y la guía turística oficial de Múnich incluye información sobre las promociones existentes en los diferentes prostíbulos.

Las condiciones de las mujeres en prostitución han empeorado tanto que, si en el promedio europeo la presencia de mujeres reclutadas para el mercado prostitucional en otros países oscila entre el 60 y $70 \%$, en Alemania representa ya el $95 \%$. En su gran mayoría, procedentes de países o contextos empobrecidos con elevados índices de exclusión social y desigualdad de género. En la medida que las condiciones en las que se practica la prostitución y que conducen a la misma parten del abuso de poder y de la situación de vulnerabilidad definitorios del delito de trata de seres humanos con fines de explotación sexual ${ }^{33}$, este porcentaje invita a la sospecha sobre el incremento de la trata y la validez legal del consentimiento.

$\mathrm{Y}$, si bien es cierto que técnicamente se prohibió el proxenetismo, no ha sido difícil esquivarlo. Los proxenetas regularizan su situación convirtiéndose en empresarios hoteleros que, simplemente, alquilan costosas habitaciones a trabajadoras sexuales. Constatado el desolador panorama, la reforma legislativa de julio de 2017 prohibió también la licencia de actividad a personas con antecedentes penales y reguló el uso obligatorio del preservativo. Pero, de momento, poco ha cambiado.

La experiencia alemana revela que la protección de las mujeres prostituidas se ha visto mermada y ha supuesto un reclamo para el proxenetismo y la trata sexual ${ }^{34}$. La reglamentación ha convertido a las redes y proxenetas en reputados "empresarios del sexo". Un contexto que, según la propia Fiscalía alemana, está dificultando la persecución de la trata de seres humanos con fines de explotación sexual ${ }^{35}$.

El discurso defensor de la reglamentación no sólo ignora estas externalidades de tipo penal, sino también las de tipo ético que afectan a las relaciones interpersonales generizadas y a las mujeres, en particular. La industria del sexo, en general, y el sistema prostitucional, en concreto, construye un imaginario concreto de

\footnotetext{
${ }^{32}$ Como ejemplo de los mismos, Ingeborg Kraus aporta la siguiente carta de servicios sexuales de un conocido burdel: AF (Anal con la lengua), AFF (Penetración anal con puño), AO (Todo sin preservativo, prohibido en la nueva ley), Braun-weib (Jugar con heces y esperma), DP (penetración doble o sexo con dos mujeres), EL (lamer los testículos), FFT (penetración completa con puño), FT (sexo oral sin preservativo y tragando el esperma), GB (Sexo en grupo -varios hombres- con eyaculación en la cara de la prostituta), GS (Sexo en grupo), KYP (Defecar sobre la prostituta), SW (Una mujer entre dos hombres), TBL (Sin tabúes, todo está permitido) y ZA (Lamer el ano). Disponible en la siguiente dirección electrónica: http://www.traummaennlein.de/

${ }^{33}$ La Trata de seres humanos con fines de explotación sexual (TSHS) representa un delito internacional definido en el artículo 3 del Protocolo para Prevenir, Reprimir y Sancionar la Trata de Personas que complementa la Convención de Naciones Unidas contra la Delincuencia Organizada de 2000 (comúnmente conocido como Protocolo de Palermo de Naciones Unidas). El citado protocolo define la TSHS como "la captación, el transporte, la recepción o la acogida de seres humanos mediante amenaza, engaño, utilización de la fuerza, abuso de poder o de una situación de vulnerabilidad o intercambio de pagos o beneficios con personas que tengan autoridad sobre la víctima, con fines de explotación".

${ }^{34}$ En el caso español, la reforma del código penal de 1995 despenalizó de facto el proxenetismo e implicó un incremento notable de las mafias de trata y tráfico con fines de explotación sexual (Gómez, Pérez y Verdugo, 2015).

${ }^{35}$ Según recoge el Informe Honeyball, "un tercio de los fiscales alemanes han observado que legalizar la prostitución ha hecho más difícil su trabajo de persecución del tráfico de seres y humanos y el proxenetismo" (Honeyball, 2013:.9). No en vano si en el año 2000 hubo 151 personas condenadas por tráfico de personas, diez años después -en pleno auge del mercado prostitucional-su número se redujo a 32. Año en el que la policía alemana registró 636 casos de mujeres traficadas, tres veces menos que la década anterior.
} 
lo que es una mujer, erotiza la dominación femenina, banaliza su sometimiento y fetichiza su explotación sexual. Como señala Beatriz Gimeno (2012: 203) "regular la prostitución, y aun cuando entendiéramos que este es un deseo legítimo de algunas mujeres que se dedican a ello, no tiene poder para cuestionar los roles de género, sino más bien los refuerza ya que su propia existencia es consecuencia de los mismos". Legalizar la prostitución, por ello, supone legitimar la concepción de las mujeres como cuerpos sexualizados y deshumanizados de los que es posible disponer de forma festiva y acrítica.

\section{Conclusiones}

En los patriarcados por consentimiento las relaciones de pareja se han democratizado y la actividad sexual de los hombres requiere el beneplácito de su contraparte; la disponibilidad sexual y reproductiva de las mujeres ya no está garantizada. Pero la masculinidad hegemónica tradicional se construye sobre una superioridad del varón que requiere, por una parte, sumisión femenina y, por otra, una sexualidad expansiva, entendida como proactiva y con diferentes mujeres ${ }^{36}$. La prostitución permite representar la performance de esta concepción de la masculinidad. Como apunta Marcela Lagarde (2001: 578) "ir con prostitutas es un verdadero simulacro de masculinidad en particular de machismo, es una teatralización del poder patriarcal".

Es preciso evidenciar la trampa que supone que, precisamente, cuando las mujeres han adquirido la condición de sujetos y la igualdad de género forma parte de los compromisos internacionales, la defensa histórica del derecho patriarcal de acceso a los cuerpos de las mujeres y la mercantilización del uso de las más vulnerables se presente como una innovación normativa solidaria, transgresora o revolucionaria.

Conviene advertir que, lejos de esta peculiar representación de la prostitución, esta representa una sólida institución del derecho sexual patriarcal cuya expansión es paralela a una ideología neoliberal donde todo puede ser mercantilizable; con las únicas restricciones de los límites legales y la capacidad económica de cada cual. Por ello, es ineludible repensar los límites del mercado y visibilizar los elementos culturales y los intereses económicos que subyacen tras un sistema prostitucional que no interpela ni transgrede orden económico o de género alguno.

Como se ha corroborado en el examen del caso alemán, regular la prostitución en el marco de las relaciones laborales no mejora las condiciones de vida de las mujeres en prostitución ni evita su estigmatización, pero sí la de puteros, proxenetas y de un sistema prostitucional en su conjunto que puede expandirse bajo el amparo de la legalidad. Por ello, es preciso apostar por legislaciones abolicionistas que abandonen la indiferencia hacía las mujeres y la complicidad con la cultura prostitucional. Se ha de trasladar el peso del estigma de las mujeres prostituidas hacia toda la cultura prostitucional: proxenetas, puteros o cualquiera que obtenga lucro de la explotación sexual ajena (desde la tercería locativa, hasta los anuncios en prensa o el PIB de los Estados).

Nadie ignora que las personas que ejercen la prostitución son mujeres, mujeres en situación de vulnerabilidad económica y/o legal, en condiciones muy alejadas de la "vida alegre", el glamour o la transgresión que algunos discursos pretenden preconizar. Por ello, si existe pretensión alguna por evitar la explotación de

\footnotetext{
${ }^{36}$ Como reflejan los resultados de las investigaciones de Gómez, Pérez y Verdugo (2015: 175) "responde a una estrategia (no necesariamente consciente) de reforzamiento de una masculinidad conformada por una identidad que gira en torno a la exhibición frente al grupo de pares del "uso del falo" y de la práctica sexual frecuente con diferentes mujeres".
} 
mujeres y niñas y promover sociedades más justas e igualitarias, se ha de abordar una reforma legislativa que tome como modelo el caso de Suecia, Islandia, Noruega o Francia. Es decir, activar políticas públicas que apoyen a las mujeres prostituidas, luchen contra los contextos de vulnerabilidad que alimentan el mercado prostitucional, penalicen el consumo y reformen una legislación en materia de publicidad, que si bien prohíbe anuncios de algunas prácticas dañinas (como el consumo de alcohol o tabaco) admite sin reservas los de prostitución.

Porque, como ha denunciado reiteradamente el feminismo desde sus orígenes, la lucha contra la jerarquía sexual pasa ineludiblemente por afianzar una concepción de las mujeres que se aleje de su consideración como objetos sexuales o reproductivos. Y ello requiere desafiar una narrativa patriarcal que erotiza la dominación, sexualiza a mujeres y niñas mientras presenta la prostitución como una forma de libertad sexual.

\section{Bibliografía}

A. V. C. (2017), "Qué es el juego del muelle y por qué es tan peligroso para la salud", 9 de enero. Disponible en: https://www.elconfidencial.com/alma-corazonvida/2017-01-09/juego-muelle-que-es-ruleta-sexual-adolescentes 1313845/ (fecha de consulta: 3 de julio de 2018.

BARRY, K. (1994) "Teoría del feminismo radical: política de la explotación sexual". En: AMORÓS, C. (ed.), Historia de la Teoría Feminista, Instituto de Investigaciones Feministas UCM, Madrid, PP. 297-309.

CENTRO DE INVESTIGACIONES SOCIOLÓGICAS (2009), Encuesta Nacional sobre Salud sexual. Centro de Investigaciones Sociológicas (ES2780: 22), 2009.

CONGRESO DE LOS DIPUTADOS (2007), Informe de la Ponencia sobre prostitución en España (154/9), Comisión Mixta de los Derechos de la Mujer y de la Igualdad de Oportunidades, Cortes Generales, Madrid.

CONGRESO DE LOS DIPUTADOS (2015), Informe de la Subcomisión para el análisis y estudio de la trata de seres humanos con fines de explotación sexual. Conclusiones y recomendaciones, Comisión de igualdad. Ministerio de Sanidad, Servicios Sociales e Igualdad, Madrid.

COBO, R. (2017), La prostitución en el corazón del capitalismo, Catarata, Madrid.

DE MIGUEL, A. y PALOMO, E. (2011), "Los inicios de la lucha feminista contra la prostitución. Políticas de redefinición y políticas activistas en el sufragismo inglés", Revista BROCAR, núm. 35, pp. 315-334.

DE MIGUEL, A. (2012), "La prostitución de mujeres, una escuela de desigualdad humana", Revista europea de derechos fundamentales, núm. 19, pp. 49-74.

DE MIGUEL, A. (2014), "Entrevista a Amelia Valcárcel”, Revista Dilemata, núm 16, pp. 199-206.

DE MIGUEL, A. (2015), Neoliberalismo sexual, el mito de la libre elección, Cátedra, Madrid.

EKIS EKMAN, K. (2017), El Ser y la mercancía. Prostitución, vientres de alquiler y disociación, Bellaterra, Barcelona.

FALUDI, S. (1993), Reacción: La guerra no declarada contra la mujer moderna, Anagrama, Barcelona.

FEDERICI, S. (2013), Revolución en punto cero. Trabajo doméstico, reproducción y luchas feministas, Traficantes de sueños, Madrid.

FRAISSE, G. (2011), Del consentimiento. Palinodia, Santiago de Chile.

GIMENO, B. (2012), La prostitución, Bellaterra, Barcelona.

GÓMEZ, Á., PÉREZ, S. y VERDUGO, R. M. (2015), El putero español. Quiénes son y qué buscan los clientes de la prostitución, Catarata, Madrid. 
GREER, G. (2004), La mujer eunuco, Kairós, Barcelona.

GUILLÓ, C. y SANTIAGO, P. (2017), "Trata, prostitución y turismo sexual. España en la intersección”. En: NUÑO GÓMEZ, L. y DE MIGUEL, A. (eds.), Elementos para una teoría crítica del sistema prostitucional, Comares, Granada, pp. 193-206.

HONEYBALL, M. (2013), Informe sobre explotación sexual y prostitución y su impacto en la igualdad de género. Disponible en: http://www.europarl.europa.eu/sides/getDoc.do?pubRef=//EP//TEXT+REPORT+A7-2014-0071+0+DOC+XML+V0//ES (fecha de consulta: 3 de agosto de 2018).

KRAUS, I. y MAIER, U. (2016), Medien und Prostitution. Disponible en: https://somoslamitad.wordpress.com/2016/11/14/el-modelo-aleman-estacreando-el-infierno-en-la-tierra/ (fecha de consulta: 3 de julio de 2018).

LAGARDE, M. (2001), Los cautiverios de las mujeres, Horas y horas, Madrid, LOZANO, M. (2017), El Proxeneta, Al revés, Barcelona.

MILLETT, K. (1977), Sexual Politics, Virago, Londres.

MACKINNON, C. A. (1989), Towards a Feminist Theory of State, Harvard University Press, Cambridge.

MENESES, C., UROZ J., y RÚA, A. (2015), Apoyando a las víctimas de trata: las necesidades de las mujeres víctimas de trata con fines de explotación sexual desde la perspectiva de las entidades especializadas y profesionales involucrados. Propuesta para la sensibilización contra la trata, Ministerio de Sanidad, Igualdad y Servicios Sociales, Madrid.

MOSCOSO, M. (2017), "El precio de la inclusión. La asistencia sexual a debate". En: NUÑO, L. y DE MIGUEL, A. (eds.), Elementos para una teoría crítica del sistema prostitucional, Comares, Granada, pp. 231-240.

NUÑO, L. (2016), "Una nueva cláusula del Contrato Sexual: vientres de alquiler", Revista Isegoría. Revista de Filosofía Moral y Política, núm. 55, pp. 683-700.

NUÑO, L. (2017) "La trata de seres humanos con fines de explotación sexual propuestas para un cambio de paradigma en la orientación de las políticas públicas", Revista de Derecho Político, núm. 98, pp. 159-187.

NUÑO, L. y DE MIGUEL, A. (2017), Elementos para una teoría crítica del sistema prostitucional, Comares, Granada.

PULEO, A. (1995), "Patriarcado". En: AMORÓS, C. (dir.), Diez palabras clave sobre Mujer, Verbo Divino, Estella, pp. 21-54.

SANDEL, M. (2013), Lo que el dinero no puede comprar, Debate, Madrid.

SASSEN, S. (2000), "Women's burden: Counter-geographies of globalization and the feminization of survival", Journal of International Affairs, núm. 53, pp. 503-524.

SCHÄFER, T. (2017), "La nueva ley de prostitución alemana prohíbe la tarifa plana de sexo", 26 de junio. Disponible en: https://www.lamarea.com/2017/06/26/fin-de-latarifa-plana-de-sexo-en-alemania/ (fecha de consulta: 3 de julio de 2018.

SIMMEL, G. (1990) The Philosophy of money, Routledge, Londres.

TAMPEP (2017), TAMPEP respecto a la situación de las trabajadoras sexuales nacionales y migrantes en la Europa actual. Disponible en: https://tampep.eu/wpcontent/uploads/2017/11/TAMPEP-paper-ESP.pdf (fecha de consulta: 3 de julio de 2018).

THILL, M. (2017), "La Unión Europea ante la explotación de la prostitución de mujeres: tensiones entre Mercado e igualdad de género". En: NUÑO, L. y DE MIGUEL, A., Elementos para una teoría crítica del sistema prostitucional, Comares, Granada, pp. 31-42.

UNODC (2010), Trafficking in Persons to Europe for sexual exploitation, Viena.

UNODC (2012), Trata de personas: delincuencia organizada y venta multimillonaria de personas", Viena.

WOLF, N. (1992) El mito de la belleza. Barcelona: Salamandra. 